\title{
Relative $\mathrm{O}\left({ }^{1} \mathrm{D}\right)$ Quantum Yields in the near UV Photolysis of Ozone at $298 \mathrm{~K}$
}

\author{
G. K. Moortgat and P. Warneck \\ Max-Planck-Institut für Chemie (Otto-Hahn-Institut), Mainz
}

(Z. Naturforsch. 30 a, 835-844 [1975] ; received April 23, 1975)

\begin{abstract}
Mixtures of $\mathrm{O}_{3}$ with excess $\mathrm{N}_{2} \mathrm{O}$ were photolysed in the wavelength region $290-335 \mathrm{~nm}$ using monochromatic light with a band width of $4 \mathrm{~nm}$. The resulting primary product atomic singlet oxygen, $\mathrm{O}\left({ }^{1} \mathrm{D}\right)$, in reacting with $\mathrm{N}_{2} \mathrm{O}$ produces in part $\mathrm{NO}$ which subsequently reacts with $\mathrm{O}_{3}$ giving rise to a weak infrared chemiluminescence. The emission was monitored with a cooled photomultiplier. The emission intensity is directly proportional to the rate of $\mathrm{O}\left({ }^{1} \mathrm{D}\right)$ production and it has been utilised to derive the relative $\mathbf{O}\left({ }^{1} \mathrm{D}\right)$ quantum yield as a function of wavelength between 295 and $320 \mathrm{~nm}$. The data were normalised to a quantum yield of unity of $300 \mathrm{~nm}$ and corrections were applied to reduce the error resulting from the spectral band width of photolysing radiation. The $O\left({ }^{1} \mathrm{D}\right)$ quantum yields show a temperature dependence. At $298 \mathrm{~K}$ the quantum yield is unity up to $305 \mathrm{~nm}$, then declines to zero at $319 \mathrm{~nm}$. At the dissociation limit, taken to occur at $\lambda=$ $310.3 \mathrm{~nm}$, the quantum yields is 0.57 , i. e. considerably below unity. The implications of this result as well as the tail toward longer wavelengths and the temperature dependence are discussed. Ozone absorption cross sections are also reported.
\end{abstract}

\section{Introduction}

For the atmospheric sciences, the photodissociation of ozone at wavelengths near $300 \mathrm{~nm}$ is important for two reasons: (a) radiation in this wavelength range still penetrates the stratospheric ozone layer and reaches the troposphere; and (b), one of the photolysis fragments is atomic oxygen in the first excited electronic state, ${ }^{1} \mathrm{D}_{2}$, which in contrast to ground state atomic oxygen, $\mathrm{O}\left({ }^{3} \mathrm{P}_{2}\right)$ is capable of reacting with water vapor among other species. The $\mathrm{OH}$ radicals thereby produced are considered one of the principal oxidative reactants in the chemistry of the troposphere and lower stratosphere ${ }^{1}$. It is generally accepted ${ }^{2,3}$ that the quantum yield of $\mathrm{O}\left({ }^{1} \mathrm{D}\right)$ formation from ozone is essentially unity at wavelengths below $300 \mathrm{~nm}$ and originates from the spin-allowed process

$$
\mathrm{O}_{3}\left({ }^{1} \mathrm{~A}\right)+\mathrm{h} v \rightarrow \mathrm{O}\left({ }^{1} \mathrm{D}\right)+\mathrm{O}_{2}\left(\mathrm{a}^{1} \Delta \mathrm{g}\right) .
$$

The $\mathrm{O}_{2}$ product formed simultaneously is also electronically excited. The dissociation energy of ozone is not sufficiently well known to derive the exact threshold wavelength for this process, but the thermochemical data ${ }^{4}$ suggest a value of about $310 \mathrm{~nm}$. At greater wavelengths the formation of $\mathrm{O}\left({ }^{1} \mathrm{D}\right)$ is energetically still possible via the process

$$
\mathrm{O}_{3}\left({ }^{1} \mathrm{~A}\right)+\mathrm{h} v \rightarrow \mathrm{O}\left({ }^{1} \mathrm{D}\right)+\mathrm{O}_{2}\left({ }^{3} \Sigma_{\mathrm{g}}{ }^{-}\right)
$$

Reprint requests to Prof. Dr. P. Warneck, Max-PlanckInstitut für Chemie, D-6500 Mainz, Saarstraße 23. where the $\mathrm{O}_{2}$ product molecule is now in the ground state. Since in this reaction the spin is not conserved, the $\mathrm{O}\left({ }^{1} \mathrm{D}\right)$ quantum yield should decrease considerably. Previous measurements by Jones and Wayne ${ }^{5}$ at a few isolated wavelengths indicated that, indeed, the $O\left({ }^{1} \mathrm{D}\right)$ quantum yield is nearly zero at $334 \mathrm{~nm}$. Thus, the quantum yield decreases from unity at $300 \mathrm{~nm}$ to essentially zero at $334 \mathrm{~nm}$. Within this range a variety of $\mathrm{O}\left({ }^{1} \mathrm{D}\right)$ quantum yield measurements have been made at isolated wavelengths (mostly $313 \mathrm{~nm}$ ) and with different experimental techniques. However, the results show little consistency, particularly at $313 \mathrm{~nm}$, a wavelength readily accessible from a filtered mercury lamp. A summary of results for this wavelength is presented in Table 1. The derived quantum yields range from 0.1 to 1.0 , indicating clearly that the situation is very unsatisfactory and should be improved.

This paper describes the determination of relative $\mathrm{O}\left({ }^{1} \mathrm{D}\right)$ quantum yields as a continuous function of wavelength by means of a sensitive chemiluminescence technique. The basis of this experiment is as follows: A mixture of ozone with excess nitrous oxide is photolysed with monochromatic light in the near ultraviolet spectral region. Any $\mathrm{O}\left({ }^{1} \mathrm{D}\right)$ formed reacts predominantly with $\mathrm{N}_{2} \mathrm{O}$ producing, in part, nitric oxide. The subsequent reaction of $\mathrm{NO}$ with ozone leads to the well-known infrared $(>600 \mathrm{~nm}$ ) chemiluminescence ${ }^{14}$ from product $\mathrm{NO}_{2}$. The emission is monitored with a photomultiplier. The signal is a function of the wavelength of the incident 
Table 1. $\mathrm{O}\left({ }^{1} \mathrm{D}\right)$ quantum yields from $\mathrm{O}_{3}$-photolysis at $3130 \AA .{ }^{*}$ Indicates gas pressure in torr.

\begin{tabular}{|c|c|c|c|c|}
\hline Investigator & $\varphi \mathrm{O}\left({ }^{1} \mathrm{D}\right)$ & $T\left({ }^{\circ} \mathrm{K}\right)$ & Conditions & References \\
\hline Taube & 0.40 & 277 & $\mathrm{O}_{3}$ in acidified liquid solution & 6 \\
\hline Raper, De More & $0.5 \pm 0.3$ & 87 & Condensed $\mathrm{O}_{3}$ in liquid $\mathrm{N}_{2}$ & 7 \\
\hline Raper, De More & $0.4 \pm 0.15$ & 87 & Condensed $\mathrm{O}_{3}$ in liquid $\mathrm{Ar}$ ( $\varphi$ from intercept) & 8 \\
\hline Schiff & 0.27 & & $\begin{array}{l}\text { Corrected } \varphi \text { from slopes, relative to at } 2537 \AA \text {, } \\
\text { of Ref. } 8\end{array}$ & 2 \\
\hline Castellano-Schumacher & $0.75-1.0$ & $248-298$ & Gas phase $\mathrm{O}_{3}(15-300) *$ & 9 \\
\hline Jones-Wayne & $\begin{array}{l}0.1 \\
0.1\end{array}$ & $\begin{array}{l}298 \\
298\end{array}$ & $\begin{array}{l}\text { Gas phase } \mathrm{O}_{3}(10-80) \\
\text { Gas phase } \mathrm{O}_{3}(25), \mathrm{H}_{2}(8)\end{array}$ & 5 \\
\hline $\begin{array}{l}\text { Siminaitis, Braslavsky, } \\
\text { Heicklen }\end{array}$ & $0.50 \pm 0.03$ & 298 & Gas phase $\mathrm{O}_{3}(9-34), \mathrm{N}_{2} \mathrm{O}(500)$ & 10 \\
\hline Nicolet & $0.35 \pm 0.08$ & 298 & Above work corrected for dark reaction & 11 \\
\hline Lin, De More & 0.08 & 235 & $\begin{array}{l}\text { Gas phase } \mathrm{O}_{3}(18), \text { Isobutane }(100) \\
\mathrm{O}_{2}(100), \mathrm{SF}_{6}(2070)\end{array}$ & 12 \\
\hline $\begin{array}{l}\text { Johnston et al. } \\
\text { Kuis, Simonaitis }\end{array}$ & $\begin{array}{l}0.15 \pm 0.15 \\
0.29 \pm 0.04\end{array}$ & $\begin{array}{l}? \\
293\end{array}$ & unknown & 13 \\
\hline Heicklen & $\begin{array}{l}0.22 \pm 0.04 \\
0.11 \pm 0.04 \\
0.30 \pm 0.1\end{array}$ & $\begin{array}{l}258 \\
221 \\
293\end{array}$ & $\begin{array}{l}\text { gas phase } \mathrm{O}_{3}(10-13), \mathrm{O}_{2}(56-72), \\
\mathrm{N}_{2} \mathrm{O}(356-482) \\
\text { gas phase } \mathrm{O}_{3}, \mathrm{O}_{2}, \mathrm{CCL}_{4} \text { (excess) }\end{array}$ & 11 \\
\hline This work & $0.29 \pm 0.04$ & 298 & gas phase $\mathrm{O}_{3}(0.1-20.9), \mathrm{N}_{2} \mathrm{O}(2-120)$ & \\
\hline
\end{tabular}

photolysis radiation, and it provides a measure for the relative $\mathrm{O}\left({ }^{1} \mathrm{D}\right)$ quantum yield in the photolysis of ozone. Below, we present first the equations describing the experiment, then give an account of the experimental apparatus and procedures, and finally present and discuss the observations.

\section{Equations}

In the photolysis of pure ozone, $\mathrm{O}\left({ }^{1} \mathrm{D}\right)$ formed by reaction (1) specified in the introduction reacts rapidly with ozone according to

$$
\mathrm{O}\left({ }^{1} \mathrm{D}\right)+\mathrm{O}_{3} \rightarrow \mathrm{O}_{2}{ }^{*}+\mathrm{O}_{2}
$$

where $\mathrm{O}_{2}{ }^{*}$ indicates an energy rich oxygen molecule which may or may not decompose into atoms ${ }^{2,3}$. In the presence of nitrous oxide the following additional reaction take place

$$
\begin{aligned}
\mathrm{O}\left({ }^{1} \mathrm{D}\right)+\mathrm{N}_{2} \mathrm{O} & \rightarrow \mathrm{NO}+\mathrm{NO}, \\
& \rightarrow \mathrm{N}_{2}+\mathrm{O}_{2} .
\end{aligned}
$$

Both channels occur with about equal probability ${ }^{15}$. For a small degree of photolysis the effect of $\mathrm{N}_{2}$ and $\mathrm{O}_{2}$ as quenchers of $\mathrm{O}\left({ }^{1} \mathrm{D}\right)$ may be neglected. Nitric oxide gives rise to the subsequent reactions

$$
\begin{aligned}
\mathrm{NO}+\mathrm{O}_{3} & \rightarrow \mathrm{NO}_{2}+\mathrm{O}_{2}, \\
& \rightarrow \mathrm{NO}_{2}{ }^{*}+\mathrm{O}_{2}, \\
\mathrm{NO}_{2}{ }^{*} & \rightarrow \mathrm{NO}_{2}+\mathrm{h} v(\lambda>600 \mathrm{~nm}), \\
\mathrm{NO}_{2}{ }^{*}+\mathrm{M} & \rightarrow \mathrm{NO}_{2}+\mathrm{M}
\end{aligned}
$$

followed by further reactions of $\mathrm{NO}_{2}$ with ozone. Only a portion of the $\mathrm{NO}_{2}$ formed in reaction 4 is electronically excited ${ }^{14}$ as indicated by the asteric, and not all of the $\mathrm{NO}_{2}{ }^{*}$ molecules emit their energy as radiation, because a fraction of them undergoes quenching by collisions with $\mathrm{M}=\mathrm{N}_{2} \mathrm{O}$ or $\mathrm{O}_{3}$.

Consider now a reaction cell traversed by photolysing u.v. radiation of wavelength $\lambda$ and viewed by an infrared-sensitive photomultiplier detector (compare Figure 1). On the basis of the above reaction scheme and assuming that the product accumulation and interference are negligible, the chemiluminescence emitted from the cell and reaching the detector is given by

$$
I(\lambda)=\alpha \varphi(\lambda) I_{\mathrm{abs}}(\lambda) C
$$

where $\alpha$ is a constant geometric factor determined by the geometry of the experimental arrangement, $\varphi(\lambda)$ is the $O\left({ }^{1} \mathrm{D}\right)$ quantum yield, $I_{\text {abs }}(\lambda)$ is the amount of photolysis radiation absorbed by ozone in the region of the photolysed cell viewed by the detector and $C$ is given by

$C=\frac{\left(k_{4 \mathrm{~b}} / k_{4}\right) k_{5}}{k_{5}+k_{6}\left(\left[\mathrm{~N}_{2} \mathrm{O}\right]+\left[\mathrm{O}_{3}\right]\right)} \frac{2 k_{3 \mathrm{a}}}{\left(k_{2}\left[\mathrm{O}_{3}\right] /\left[\mathrm{N}_{2} \mathrm{O}\right]+k_{3}\right)}$

This expression involves the rate coefficients associated with reactions 2 through 6 and the concentrations of ozone and nitrous oxide. The factor $C$ will remain constant during an experiment provided the rate of photolysis is sufficiently small so that the 
concentrations of ozone and nitrous oxide are left unchanged. The absolute value of $C$ may be optimized within certain concentration limits. On one hand, the concentration of ozone must be sufficiently high to assure a reasonable amount of light absorption, on the other hand the total concentrations should be kept sufficiently low to avoid an excessive quenching of the chemiluminescence emission. The rate coefficients for reactions 2 and 3 are now well known according to two recent reviews ${ }^{16,17}$ and it appears that more than $80 \%$ of $\mathrm{O}\left({ }^{1} \mathrm{D}\right)$ formed will react with $\mathrm{N}_{2} \mathrm{O}$ in the presence of ozone, if the ratio $\left[\mathrm{N}_{2} \mathrm{O}\right] /\left[\mathrm{O}_{3}\right]$ is greater than ten.

Accepting that $C$ stays constant during a photolysis run, the $O\left({ }^{1} \mathrm{D}\right)$ quantum yield is directly proportional to the ratio $I(\lambda) / I_{\text {abs }}(\lambda)$. The total signal derived at the detector

$$
S(\lambda)=\beta I(\lambda)+B(\lambda)
$$

contains not only the signal $\beta I(\lambda)$ due to the chemiluminescence emission ( $\beta$ designating an appropriate coefficient) but also a background signal $B(\lambda)$ which is a function of $\lambda$ because it is composed of the dark current and a contribution from scattered u.v. radiation. To derive the quantum yield from the total signal one must deduct the background and obtains

$$
\varphi(\lambda)=\frac{I(\lambda)}{\alpha C I_{\mathrm{abs}}(\lambda)}=\frac{S(\lambda)-B(\lambda)}{\alpha \beta C I_{\mathrm{abs}}(\lambda)} .
$$

The amount of photolysis radiation absorbed by ozone in the observation region viewed by the photomultiplier detector must be computed from

$$
\begin{aligned}
I_{\mathrm{abs}}(\lambda)=I_{a}(\lambda)-I_{b}(\lambda)=I_{0}(\lambda) f(\lambda) \\
=I_{0}(\lambda)\left[e^{-\sigma(\lambda)\left[0_{\mathbf{s}}\right] a}-e^{-\sigma(\lambda)\left[\mathrm{O}_{\mathbf{3}}\right] b}\right]
\end{aligned}
$$

where $I_{0}(\lambda)$ is the incident light intensity, $\sigma(\lambda)$ is the ozone absorption cross section as a function of wavelength $\lambda,\left[\mathrm{O}_{3}\right]$ is the ozone number density, and $a$ and $b$ are the path lengths to the front and rear boundaries of the observation volume measured from the inner face of the entrance window of the photolysis cell. Absorption by $\mathrm{N}_{2} \mathrm{O}$ is assumed to be entirely negligible.

It is evident that equation IV provides only relative values for the $O\left({ }^{1} \mathrm{D}\right)$ quantum yield, so that a normalizing factor must be introduced. It was here assumed that $\varphi(\lambda)=1.0$ for wavelengths $\lambda \leqq 300 \mathrm{~nm}$, and the data were normalised accordingly.

In the present experiments the wavelength of photolysis radiation was selected from a continuum source by means of a monochromator with finite resolution. Hence, the derived quantum yield data are averages over a certain range of wavelengths. From the above equations one obtains

$$
\bar{\varphi}(\lambda)=\frac{\int \varphi(\lambda+\xi) I_{0}(\lambda+\xi) f(\lambda+\xi) S(\xi) \mathrm{d} \xi}{\int I_{0}(\lambda+\xi) f(\lambda+\xi) S(\xi) \mathrm{d} \xi}
$$

where $\lambda$ is the center wavelength, $S(\xi)$ is the monochromator slit function and the integration must be performed over the range $-\infty<\xi<+\infty$. The functions underneath the integrals can be determined experimentally with exception of the desired true quantum yield function $\varphi(\lambda)$. However, this function can be derived numerically from the experimentally determined quantity $\bar{\varphi}(\lambda)$ by a series of successive approximations using a Gauss leastsquares procedure. An appropriate computing program has been applied but it will not be detailed here.

\section{Experimental Procedures}

(a) Apparatus: The experimental arrangement is sketched in Figure 1. The optical train consisted of a $150 \mathrm{~W}$ u.v. enhanced xenon are lamp, a distilledwater filter to remove excess heat, quartz focussing elements, an $f / 4$ Czerny-Turner monochromator with an additional filter and collimator lens behind the exit slit, the photolysis cell, and the thermopile detector to monitor the transmitted radiation.

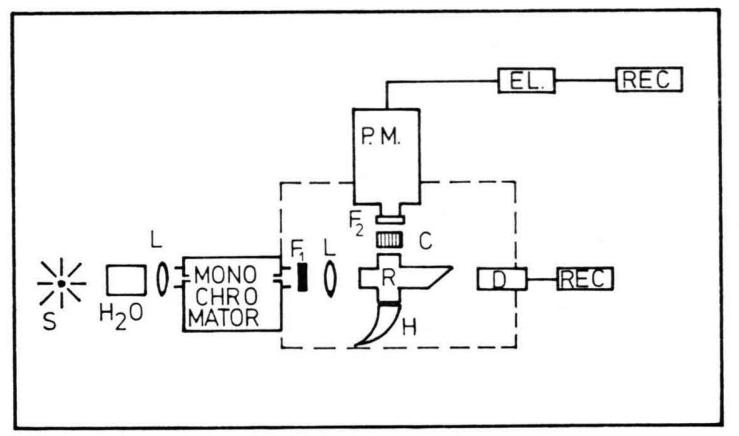

Fig. 1. Schematic diagram of photolysis system. $\mathrm{S}=$ light source, $\mathrm{H}_{2} \mathrm{O}=\mathrm{IR}$ water filter, $\mathrm{L}=$ focussing elements, $\mathrm{H}=$ Woods horn, $\mathrm{R}=$ quartz recation cell, $\mathrm{D}=$ Radiant flux detector, $F_{1}=U V$ band pass filter, $\mathrm{C}=$ collimator, $\mathrm{F}_{2}=$ UV cut-off filter, $\mathrm{PM}=$ photomultiplier, $\mathrm{EL}=$ electrometer, $\mathrm{REC}=$ recorder.

The monochromator had a focal length of $220 \mathrm{~mm}$ and was fitted with $1.25 \mathrm{~mm}$ wide slits resulting in a resolution of about $4 \mathrm{~nm}$ at half width. The slit function was determined using the $253.7 \mathrm{~nm}$ mercury line. The same slit function was assumed to 
apply also in the $300 \mathrm{~nm}$ wavelength region. The $253.7 \mathrm{~nm}$ and $313.1 \mathrm{~nm}$ mercury lines were also used to calibrate the wavelength scale of the monochromator within $\pm 0.3 \mathrm{~nm}$ accuracy. The 1200 lines $/ \mathrm{mm}$ grating was blazed for $300 \mathrm{~nm}$. It was rotated via a motor driven gear assembly. The resulting wavelength scanning speed was $12 \mathrm{~nm}$ per minute. Although the maximum efficiency of the grating was $70 \%$ and the level of scattering was specified as less than $0.05 \%$, the stray light was too high and a further reduction was required. A $6 \mathrm{~mm}$ Schott UG 11 filter was inserted behind the monochromator exit for this purpose. The transmission of the filter was $50 \%$ at $335 \mathrm{~nm}$ and less than $10^{-3}$ percent at wavelengths $\lambda<250 \mathrm{~nm}$ and $\lambda>400 \mathrm{~nm}$. A quartz lens and an additional $20 \mathrm{~mm}$ aperture served to collimate the radiation into an approximately parallel beam of light so that the direct reflection of light from the photolysis cell was minimized. The photolysis cell was a cross of $40 \mathrm{~mm}$ diameter Suprasil quartz tubing to which $3 \mathrm{~mm}$ quartz windows were heat-sealed. The end window allowing the transmitted radiation to escape was set at an angle of 40 degrees in order that the reflected portion of light did not re-enter the photolysis region. The chemiluminescent emission was observed perpendicular to the optical axis with a dry icecooled photomultiplier followed by an electrometer and strip-chart recorder. The employed EMI $9659 \mathrm{~B}$ type photomultiplier features an extended S-20 response. A collimating honey comb structure in front of the photomultiplier limited the observation region within the photolysis cell to a space $30 \mathrm{~mm}$ in width, its center being located $49.5 \mathrm{~mm}$ behind the rear plane of the entrance window. A $3 \mathrm{~mm}$ thick Schott OG 590 short wave cut-off filter was placed in front of the photomultiplier. Its transmittance was less than $10^{-3}$ at wavelengths below $560 \mathrm{~nm}$. The major portion of scattered light in the u.v. spectral region was thus removed. A Wood's horn opposite the photomultiplier also served to reduce the effect of scattered light. The photomultiplier currents observed with the empty photolysis cell or with a filling of $\mathrm{N}_{2} \mathrm{O}$ ranged from the dark current value of $7 \times 10^{-11} \mathrm{~A}$ to about twice that amount. The maximum signals observed during the $\mathrm{O}_{3}$ photolysis were by a factor of about twenty greater.

(b) Materials: A conventional mercury-free gas handling system was used for the preparation, purification and mixing of gases. Ozone was generated from $\mathrm{P}_{2} \mathrm{O}_{5}$-dried, prepurified oxygen flowing through a Siemens-type ozoniser powered by a $15 \mathrm{kV}$ neon transformer. The ozone was trapped on silica-gel cooled with dry ice. After a sufficient amount had accumulated, the ozoniser and the $\mathrm{O}_{2}$ flow were shut off, and the excess oxygen was pumped out through a trap containing molecular sieve and silver wire. Subsequently, the ozone was freed from the remaining oxygen by condensation at liquid nitrogen temperature and degassing. Nitrous oxide from a steel cylinder (99.9\% purity) was further purified by bulb to bulb destillation. The gases were mixed before admitting them to the evacuated photolysis cell. Pressures of ozone and of $\mathrm{N}_{2} \mathrm{O}$-ozone mixtures below 50 Torr were measured with a sulfuric acidfilled U-shaped manometer. Higher pressures of $\mathrm{N}_{2} \mathrm{O}$ were determined with a mechanical pressure gauge. Ozone partial pressures in the photolysis cell were in addition determined from the extent of light absorption at wavelengths $300<\lambda<310 \mathrm{~nm}$ using absorption parameters obtained separately as described below.

(c) Ozone absorption cross sections: Although quantitative data are given in the literature ${ }^{18-20}$ it was found necessary to redetermine the $\mathrm{O}_{3}$ absorption cross sections with the present optical set-up because of the influence which the Huggins bands exert in combination with the finite spectral resolution of the equipment, and because the literature data appear predominantly in graphical form whereas more precise numerical values are required here. The cross sections determinations were made as is customary from the ratio of incident to transmitted radiation intensities, using a quartz cell of $6.75 \mathrm{~cm}$ path length filled with triply distilled ozone.

(d) Data evaluation: According to Eqs. (IV) and (V) the determination of the $\mathrm{O}\left({ }^{1} \mathrm{D}\right)$ quantum yield involves the knowledge or measurement of the following quantities: the ozone absorption cross sections $\sigma(\lambda)$, the photolysis cell geometry ( $a$ and $b$ ), the $\mathrm{O}_{3}$ concentration, the incident radiation intensity $I_{0}(\lambda)$, the photomultiplier signal $S(\lambda)$, and the background signal $B(\lambda)$. The first three quantities were obtained by auxiliary measurements. The remaining quantities were obtained from the multiplier signal and the signal derived at the thermopile detector. Both were recorded simultaneously, while the wavelength was scanned, for two experimental conditions: (1) when the cell was filled with an appropriate mixture of $\mathrm{O}_{3}$ and $\mathrm{N}_{2} \mathrm{O}$, and (2) before and after each photolysis run with the cell being evacuated. A typical example for the resulting raw data is shown in Figure 2. The signal from the thermopile detector obtained with the empty cell was taken to represent $I_{0}(\lambda)$. Usually, the curves observed before and after a run coincided once the lamp had stabilized. Slight deviations were taken into account by averaging. During a photolysis run the radiation intensity transmitted by the cell is decreased due to absorption by ozone. The corre- 
sponding signal $I_{\mathrm{t}}(\lambda)$ of the thermopile detector was utilized to determine independently the partial $\mathrm{O}_{3}$ pressure in the cell from the knowledge of the cell length and the ozone absorption cross sections in the wavelength range $300<\lambda<310 \mathrm{~nm}$. The photomultiplier signal $S(\lambda)$ from a photolysis run was used directly after smoothing somewhat the superimposed noise. The background signal observed with the empty cell could not be used in the same manner, because it involves in addition to the dark current a contribution from scattered light which is subject to absorption by ozone in a photolysis run. Hence, an appropriate correction using Beer's law was applied. The correction is only approximate, since the points of origin of the scattered radiation are not known. It was here assumed that the signal due to scattering decreased mainly as a result of absorption of the incident radiation. The applicable absorption path-length is then the distance between the rear face of the front window of the photolysis cell and the center of the emission region viewed by the photomultiplier. The corrected background signal is also shown in Fig. 2 together with the other data.

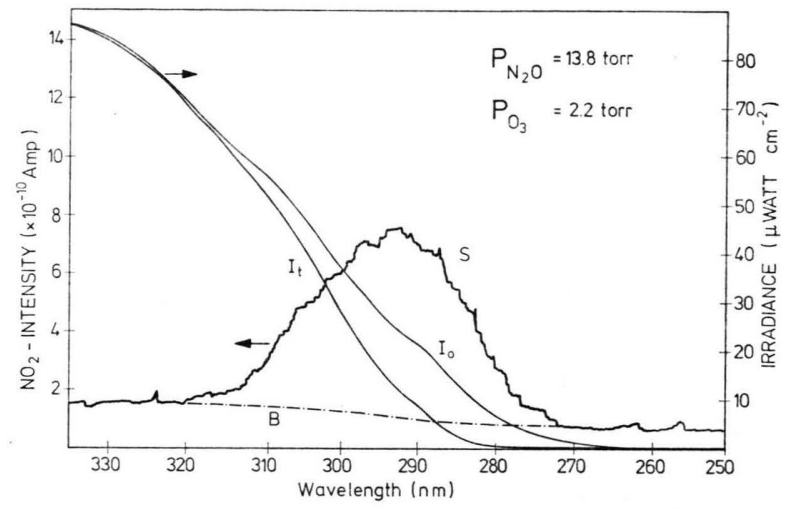

Fig. 2. Chemiluminescent trace of $\mathrm{NO}_{2}$ emission, ranging from $250 \mathrm{~nm}$ to $330 \mathrm{~nm}$. B = calculated background level (see text), $I_{\mathrm{t}}=$ Transmitted light intensity, $I_{0}=$ Incident light intensity, $\mathrm{S}=$ Photomultiplier Signal.

\section{Results}

(a) Ozone absorptions cross sections determined in this study at selected wavelengths are entered in Table 2. Despite the limited spectral resolution

\begin{tabular}{|c|c|c|c|c|c|c|}
\hline$\lambda(\mathrm{nm})$ & $\sigma\left(\mathrm{cm}^{2}\right)$ & $\varphi\left(\mathrm{O}^{1} \mathrm{D}\right)$ & $\lambda(\mathrm{nm})$ & $\sigma\left(\mathrm{cm}^{2}\right)$ & \multicolumn{2}{|c|}{$\varphi\left(\mathrm{O}^{1} \mathrm{D}\right)$} \\
\hline 297.5 & $5.75(-19)$ & $1.00 \pm 0.01$ & 314.0 & $6.17(-20)$ & 0.21 & \pm 0.03 \\
\hline 298.0 & $5.14(-19)$ & & 314.5 & $5.76(-20)$ & 0.17 & \pm 0.025 \\
\hline 298.5 & $4.92(-19)$ & & 315.0 & $5.22(-20)$ & 0.14 & \pm 0.02 \\
\hline 299.0 & $4.67(-19)$ & & 315.5 & $5.30(-20)$ & 0.11 & \pm 0.02 \\
\hline 299.5 & $4.36(-19)$ & & 316.0 & $4.56(-20)$ & $0.078=$ & \pm 0.015 \\
\hline 300.0 & $4.09(-19)$ & & 316.5 & $4.09(-20)$ & $0.054=$ & \pm 0.015 \\
\hline 300.5 & $3.85(-19)$ & & 317.0 & $4.27(-20)$ & $0.037=$ & \pm 0.01 \\
\hline 301.0 & $3.55(-19)$ & & 317.5 & $3.83(-20)$ & 0.022 & \pm 0.01 \\
\hline 301.5 & $3.31(-19)$ & & 318.0 & $3.65(-20)$ & 0.011 & \pm 0.01 \\
\hline 302.0 & $3.13(-19)$ & & 318.5 & $3.20(-20)$ & $0.004=$ & \pm 0.01 \\
\hline 302.5 & $2.91(-19)$ & $\downarrow$ & 319.0 & $3.00(-20)$ & 0.0005 & \pm 0.008 \\
\hline 303.0 & $2.71(-19)$ & $1.00 \pm 0.01$ & 319.5 & $2.86(-20)$ & & 0.0 \\
\hline 303.5 & $2.52(-19)$ & $1.00 \pm 0.015$ & 320.0 & $3.15(-20)$ & & 0.0 \\
\hline 304.0 & $2.32(-19)$ & $1.00 \pm 0.015$ & 320.5 & $2.51(-20)$ & & 个 \\
\hline 304.5 & $2.14(-19)$ & $0.99 \pm 0.02$ & 321.0 & $2.04(-20)$ & & \\
\hline 305.0 & $2.05(-19)$ & $0.98 \pm 0.02$ & 321.5 & $1.94(-20)$ & & \\
\hline 305.5 & $1.88(-19)$ & $0.97 \pm 0.025$ & 322.0 & $2.12(-20)$ & & \\
\hline 306.0 & $1.77(-19)$ & $0.95 \pm 0.03$ & 322.5 & $2.20(-20)$ & & \\
\hline 306.5 & $1.64(-19)$ & $0.93 \pm 0.035$ & 323.0 & $1.78(-20)$ & & \\
\hline 307.0 & $1.50(-19)$ & $0.90 \pm 0.04$ & 323.5 & $1.55(-20)$ & & \\
\hline 307.5 & $1.36(-19)$ & $0.87 \pm 0.05$ & 324.0 & $1.35(-20)$ & & \\
\hline 308.0 & $1.28(-19)$ & $0.83 \pm 0.05$ & 324.5 & $1.73(-20)$ & & \\
\hline 308.5 & $1.19(-19)$ & $0.78 \pm 0.06$ & 325.0 & $1.55(-20)$ & & \\
\hline 309.0 & $1.12(-19)$ & $0.73 \pm 0.06$ & 325.5 & $1.25(-20)$ & & \\
\hline 309.5 & $1.06(-19)$ & $0.67 \pm 0.06$ & 326.0 & $1.08(-20)$ & & \\
\hline 310.0 & $0.79(-20)$ & $0.60 \pm 0.055$ & 326.5 & $9.50(-21)$ & & \\
\hline 310.5 & $9.31(-20)$ & $0.54 \pm 0.055$ & 327.0 & $9.20(-21)$ & & \\
\hline 311.0 & $8.88(-20)$ & $0.49 \pm 0.05$ & 327.5 & $1.13(-20)$ & & \\
\hline 311.5 & $8.26(-20)$ & $0.43 \pm 0.05$ & 328.0 & $1.15(-20)$ & & \\
\hline 212.0 & $7.57(-20)$ & $0.38 \pm 0.05$ & 328.5 & $9.10(-21)$ & & \\
\hline 312.5 & $7.31(-20)$ & $0.34 \pm 0.045$ & 329.0 & $6.58(-21)$ & & \\
\hline 313.0 & $6.72(-20)$ & $0.29 \pm 0.04$ & 329.5 & $5.43(-21)$ & & $\downarrow$ \\
\hline 313.5 & $7.00(-20)$ & $0.25 \pm 0.04$ & 330.0 & $6.33(-21)$ & & 0.0 \\
\hline
\end{tabular}

Table 2. $\mathrm{O}_{3}$-absorption cross sections and $\mathbf{O}\left({ }^{1} \mathrm{D}\right)$ quantum yields at $298^{\circ} \mathrm{K}$. 
employed here, the results are in excellent agreement with the data reported by Griggs ${ }^{20}$ and by Inn and Tanaka ${ }^{19}$ except at the wavelengths where the stronger features of the Huggins bands appear $(\lambda>318 \mathrm{~nm})$. At the maximum of these bands the present cross sections are lower as expected on account of the limited spectral resolution. As it turns out this effect has not much consequences for the determination of the $\mathrm{O}\left({ }^{1} \mathrm{D}\right)$ quantum yield, because the strong Huggins bands occur at wavelengths longer than the onset of $\mathrm{O}\left({ }^{1} \mathrm{D}\right)$ formation.

(b) $\mathrm{O}\left({ }^{1} \mathrm{D}\right)$ quantum yields: A greater variety of runs was performed using different mixing ratios of the photolysis components $\mathrm{O}_{3}$ and $\mathrm{N}_{2} \mathrm{O}$ with partial pressures of ozone ranging from 0.1 to 20.9 Torr, and total pressures ranging from 2 to 120 Torr. There was no noticeable effect of the pressure or the mixing ratio on the shape of the observed quantum yield curve. However, at high total pressures the signal to noise ratio became less satisfactory. From the sum of the raw data, an example of which is shown in Fig. 2, seven runs with optimum signal to noise ratio were selected for averaging. The resulting relative quantum yield curve, normalized to unity at $\lambda=300 \mathrm{~nm}$, is shown in Fig. 3 by the shaded area. Its boundaries indicate the most probable error. Pertinent data of other investigators are also shown for comparison (see discussion further below). Finally, our data in Fig. 3 were corrected for the finite resolution of the employed monochromator, utilysing the procedure outlined to solve Equation VI. The resulting quantum

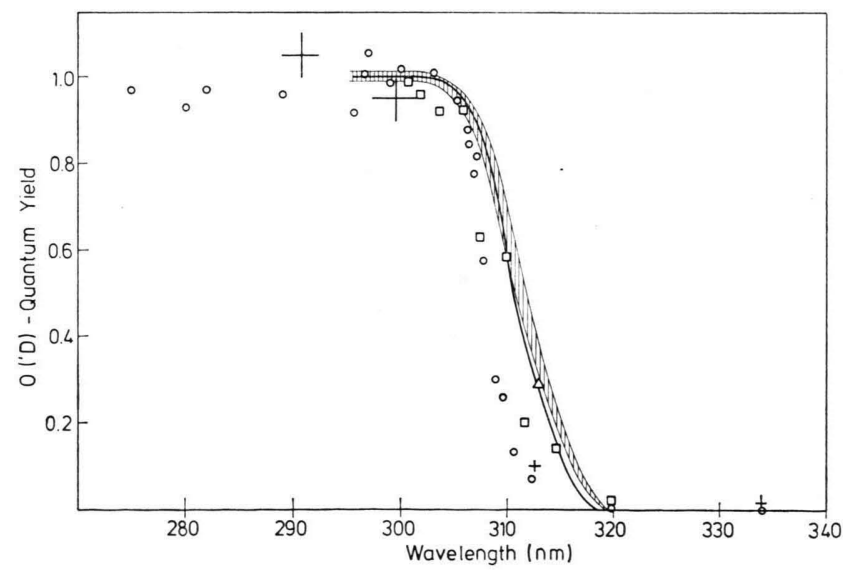

Fig. 3. The $\mathbf{O}\left({ }^{1} \mathrm{D}\right)$ quantum yield from the photolysis of $\mathrm{O}_{3}$ as a function of wavelength. $\bigcirc \mathrm{Lin}$ and De More ${ }^{11}$, + Jones and Wayne ${ }^{3}, \square$ Johnston ${ }^{12}, \triangle$ Kuis et al. ${ }^{10}$, IIII This work (see text); — This work, corrected for spectral resolution. yields are entered in Table 2 . The differences with the uncorrected values in Fig. 3 are comparatively minor.

When pure ozone was photolyzed a very weak chemiluminescence was observed. Applying the same data treatment, but setting $\left[\mathrm{N}_{2} \mathrm{O}\right]=0$, an identical quantum yield curve as shown in Fig. 3 was obtained, even though the error resulting from the poorer signal to noise ratio was greater. This result indicates that the emission originates from a species formed either simultaneously with $\mathrm{O}\left({ }^{1} \mathrm{D}\right)$ or as a product of its reaction. Since the species responsible for the emission has not been identified in the present study, we shall not speculate on its nature. The weakness of the emission and the similarity of the derived quantum yield curve with that obtained with added $\mathrm{N}_{2} \mathrm{O}$ show, however, that the involved process does not change the results obtained when $\mathrm{N}_{2} \mathrm{O}$ is present.

The recent results of Kuis et al. ${ }^{11}$ indicate that the $O\left({ }^{1} \mathrm{D}\right)$ quantum yield depends on the temperature to some extent. The present experiments were not designed to study this effect, so that the results are valid only for a temperature of $298 \mathrm{~K}$. However, by surrounding the photolysis cell with a box filled with dry ice it was shown that a temperature dependence exists and that upon cooling the onset of $\mathrm{O}\left({ }^{1} \mathrm{D}\right)$ formation moves toward shorter wavelengths. A more quantitative investigation of the temperature effect requires a modification of the apparatus which is currently being carried out.

\section{Discussion}

\section{a) Comparison with Results from other Investigations}

For comparison with the present results we included in Fig. 3 those of the previous $O\left({ }^{1} \mathrm{D}\right)$ quantum yield measurements that provide an indication of the wavelength dependence in the spectral region of interest. Specifically, we entered the results of Jones and Wayne ${ }^{5}$, Lin and De More ${ }^{12}$ and Johnston ${ }^{13}$. Also included are the data of Kuis et al. ${ }^{11}$ at the isolated wavelength $313.1 \mathrm{~nm}$ because similar to the present experiments these authors made use of the reaction of $\mathrm{O}\left({ }^{1} \mathrm{D}\right)$ with nitrous oxide.

The most detailed of the previous results were obtained by Lin and De More ${ }^{12}$ by means of the $O\left({ }^{1} \mathrm{D}\right)$ insertion technique (the reaction with iso- 
butane was used which yields isobutanol). The agreement with the present data is rather poor in that the quantum yield curve derived by Lin and De More is steeper and the threshold of $\mathrm{O}\left({ }^{1} \mathrm{D}\right)$ formation occurs at a lower wavelength. In searching for causes of the discrepancy we have investigated the effects of pressure and spectral resolution. The influence of these parameters is not strong enough to provide a reasonable explanation for the discrepancy. Temperature appears to be a much more important parameter. Indeed, the experiments of Lin and De More ${ }^{12}$ were performed at $235 \mathrm{~K}$, about 60 degrees below the temperature of the present experiments. In addition, Kuis et al. ${ }^{11}$ have shown very recently that at the isolated wavelength $313.1 \mathrm{~nm}$ the $\mathbf{O}\left({ }^{1} \mathrm{D}\right)$ quantum yield decreases from $\varphi=0.29$ at $293 \mathrm{~K}$ to $\varphi=0.11$ at $221 \mathrm{~K}$. Accordingly, we ascribe the observed differences in the quantum yield curve between Lin and De More's results and ours to the difference in the employed temperatures. The results of Jones and Wayne ${ }^{5}$ were derived at room temperature from the behaviour of the ozone quantum yield when hydrogen was added. The value of $\varphi=0.1$ obtained at $313.1 \mathrm{~nm}$ fits more closely to the curve of Lin and De More than to ours, but like many other studies making use of the $\mathrm{O}_{3}$ loss quantum yield the evaluation of the data in terms of the $\mathbf{O}\left({ }^{1} \mathrm{D}\right)$ quantum yield rests on a number of assumptions of unknown validity so that a correspondingly large error may result. The data of Johnston and collaborators are as yet unpublished and are included only in summary report by Wayne ${ }^{13}$. These data were apparently obtained by a technique similar to ours. The results are intermediate between the present results and those of Lin and De More ${ }^{12}$. The employed temperature is unknown. The very recent data of Kuis et al. ${ }^{11}$ for the wavelength $313.1 \mathrm{~nm}$ are of considerable interest in that these investigators utilized as a measure of the $O\left({ }^{1} \mathrm{D}\right)$ quantum yield from ozone the production of nitrogen which takes place concurrently with that of $\mathrm{NO}$ in the reaction of $\mathrm{O}\left({ }^{1} \mathrm{D}\right)$ with nitrous oxide (reaction $\left.3 \mathrm{~b}\right)$. Thus, they exploited the same reaction system as the present study but used a different product channel for analysis. It is remarkable that their room temperature value of the $O\left({ }^{1} \mathrm{D}\right)$ quantum yield, $\varphi=$ 0.29 , coincides exactly with that found at $\lambda=$ $313.1 \mathrm{~nm}$ in the present work. Most of the other values derived by earlier investigators and listed in Table 1 are considerably higher.

\section{b) Influence of Rotational Excitation}

The observed temperature dependence of the $\mathrm{O}\left({ }^{1} \mathrm{D}\right)$ quantum yield curve implies the importance of thermal excitation in the energy budget of the photodissociating ozone molecule. This aspect of the data will now be discussed. The excitation of both, vibrational and rotational levels contributes to the internal energy. However, the lowest vibrational frequency of ozone is $705 \mathrm{~cm}^{-1}$, corresponding to the bending mode of the ground state. At room temperature the fraction of ozone molecules excited to the first level of this vibrational mode is about $3 \%$ and the fraction of molecules in vibrational levels of higher energy is correspondingly smaller. The excitation of the rotational levels, by comparison, is much more pronounced, not only because the rotational frequencies are much smaller but also because the $2 J+1$ degeneracy causes several hundred rotational levels to participate. Consequently, we shall here consider only the contribution to photodissociation provided by the rotational excitation.

As a rotor, ozone represents an asymmetric top molecule, i. e. the three rotational constants have different values. However, two of these values are fairly similar, so that the rotational energy levels of the ozone molecule may be approximated by the symmetric top representation $h c[\bar{B} J(J+1)+$ $\left.(A-\bar{B}) K^{2}\right]$, where $A=3.5535 \mathrm{~cm}^{-1}$ and $\bar{B}=$ $\sqrt{B C}=0.4193 \mathrm{~cm}^{-1}$ are the rotational constants ${ }^{21}$, $h$ is Planck's constant, $c$ is the velocity of light and $J$ and $K$ are the rotational quantum numbers $(K \leqq J)$. The population distribution of rotational levels is given by

$$
\begin{gathered}
\left(1 / Q_{\mathrm{R}}\right)(2 J+1) \exp \{-h c[\bar{B} J(J+1) \\
\left.\left.+(A-\bar{B}) K^{2}\right] / k T\right\}
\end{gathered}
$$

where $Q_{\mathrm{R}}$ denotes the pertinent partition function. Further to be taken into account is the planar symmetry of ozone in conjunction with the nuclear spin of zero for the ${ }^{16} \mathrm{O}$ isotope of oxygen. The procedure for calculating the partition function and the mode of counting rotational levels in the case of twofold symmetry have been outlined in detail by Herzberg ${ }^{22}$. The K-type doubling ${ }^{21}$ caused by the deviation from the pure symmetric top configuration has not been taken into account. The doubling oc- 
curs for all levels except $K=0$, is largest for $K=1$ and essentially negligible for $K>3$. A probably more important effect is the centrifugal stretching which increases with increasing $J$ and $K$ and reduces the term energies. This effect has not been included here, because the required term constants are not known.

Making use of the above concepts, we have calculated the rotational population distribution at $298 \mathrm{~K}$ to derive the fraction $f_{\mathrm{R}}$ of ozone molecules residing in rotational states above a given energy level $\tilde{\nu}_{\mathrm{R}}\left(\right.$ in $\left.\mathrm{cm}^{-1}\right)$. Photodissociation from these rotational states is energetically allowed for radiation endowed with energy $\tilde{\boldsymbol{v}}=\tilde{\nu}_{0}-\tilde{v}_{\mathrm{R}}$ i.e. with energy smaller than the required dissociation energy $\tilde{v}_{0}$ by the amount $\tilde{\nu}_{R}$. Treating $\tilde{\nu}_{R}$ as a parameter, the fraction $f_{R}$ was calculated as a function of wavenumber $\tilde{\boldsymbol{v}}=\tilde{\boldsymbol{v}}_{0}-\tilde{\boldsymbol{v}}_{\mathrm{R}}$. The results are presented in Fig. 4 together with the measured $O\left({ }^{1} \mathrm{D}\right)$ quan-

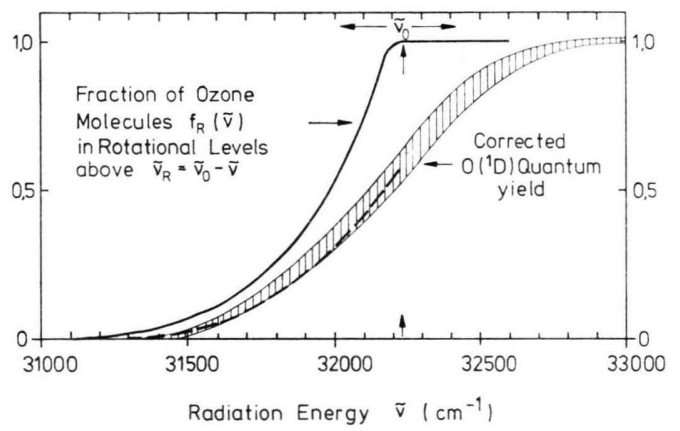

Fig. 4. Comparison of the corrected $\mathrm{O}\left({ }^{1} \mathrm{D}\right)$ quantum yield curve $(\|\| \|$ ) plotted versus the wavenumber of absorbed radiation, with the calculated fraction $f_{R}(\tilde{\nu})$ of ozone molecules (- $(-)$, endowed with rotational energy sufficient to contribute to the dissociation process at wavenumbers below the $O\left({ }^{1} \mathrm{D}\right)$ dissociation limit $\tilde{\nu}_{0}$. The assumed value of $\tilde{v}_{0}$ is indicated by the vertical arrows and corresponds to the thermal $\mathrm{O}_{2}-\mathrm{O}$ dissociation energy of $24.2 \mathrm{kcal}$. The horizontal arrows indicate the range of uncertainty of $\pm 0.5 \mathrm{kcal}$.

The dashed curve (-- $)$ respresents $0.56 f_{\mathrm{R}}(\tilde{v})$.

tum yield curve plotted versus energy in the same units. In the calculation, $\tilde{v}_{0}$ was selected on the basis of the thermal value dissociation energy $(24.2 \pm 0.5 \mathrm{kcal})$ for the process $\mathrm{O}_{3} \rightarrow \mathrm{O}_{2}\left({ }^{3} \Sigma_{\mathrm{g}}\right)$ $=\mathrm{O}\left({ }^{3} \mathrm{P}\right)$. In Fig. 4, this value is indicated by a vertical arrow. The range of values compatible with the limits of uncertainty of the thermal dissociation energy is also shown.

\section{c) Nature of the Dissociation Process}

In discussing Fig. 4 we shall first assume that the photodissociation of $\mathrm{O}_{3}$ produces $\mathrm{O}\left({ }^{1} \mathrm{D}\right)$ with $100 \%$ efficiency whenever the sum of accessible rotational and absorbed photon energy exceeds the dissociation limit, but that the production of $\mathrm{O}\left({ }^{1} \mathrm{D}\right)$ is negligible for total energies lower than the dissociation energy. One would then expect the $O\left({ }^{1} \mathrm{D}\right)$ quantum yield to reach a value of unity at the dissociation limit, i.e. somewhere in the region of wavenumbers covering the range of $\tilde{v}_{0}$ indicated in Fig. 4 ; and, for wave numbers $\tilde{v}<\tilde{v}_{0}$ the $O\left({ }^{1} \mathrm{D}\right)$ quantum yield curve should follow closely the fraction $f_{\mathrm{R}}$ of ozone molecules provided with rotational energy sufficient to enable the photodissociation process despite the lower radiation energy. Figure 4 demonstrates, however, that both predictions are not borne out by the observations. The $\mathrm{O}\left({ }^{1} \mathrm{D}\right)$ quantum yield becomes unity about $400 \mathrm{~cm}^{-1}$ above the range of the dissociation limit, and the calculated rotational contribution to the dissociation process declines much more steeply with decreasing energy than the observed $\mathrm{O}\left({ }^{1} \mathrm{D}\right)$ quantum yield. Both sets of data may be reconciled only, if the dissociation limit lies near $32800 \mathrm{~cm}^{-1}$ and the rotational population distribution is spread over a wider range of energies implying that the calculation has been performed on the basis of grossly incorrect assumptions. Such a coincidence of adverse factors is considered rather unlikely. Kuis et al. ${ }^{11}$ have also suggested that in order to conserve angular momentum in the dissociation process, the energies residing in certain rotational levels may be unavailable ${ }^{23}$. The incorporation of their concept in the calculation of the fractional rotational energy curve $f_{\mathrm{R}}$ results in a curve that declines even more steeply with decreasing energy than that shown in Figure 4 . The discrepancy with the observational data is thereby enhanced and not alleviated. Consequently, these considerations lead to the conclusion that the assumption of unity $\mathrm{O}\left({ }^{1} \mathrm{D}\right)$ quantum yield immediately above the dissociation limit cannot be maintained. Only a fraction of all the transitions into this energy regime leads to the production of $\mathrm{O}\left({ }^{1} \mathrm{D}\right)$. The magnitude of this fraction can be estimated by comparison of the calculated curve $f_{R}$ with the observed quantum yield curve, both shown in Figure 4. A fraction of $0.57 f_{\mathrm{R}}$, shown in Fig. 4 by the dashed line, lies within the range of observational data indicated by the hatched area. With increasing energy above the dissociation limit, of course, a quantum yield of unity is eventually reached. 
Further considerations must deal with the origin of the reduced efficiency of $\mathbf{O}\left({ }^{1} \mathrm{D}\right)$ production in the energy domain about $400 \mathrm{~cm}^{-1}$ above the dissociation limit. Theoretical predictions ${ }^{24,} 25$ indicate the existence of one strong electronic transition in the near ultraviolet spectral region, ${ }^{1} \mathrm{~B}_{2} \leftarrow \mathrm{X}^{1} \mathrm{~A}_{1}$, and the Hartley continuum must represent at least a portion of this transition. If the potential surface of the involved upper state were purely repulsive, one would expect the $O\left({ }^{1} \mathrm{D}\right)$ quantum yield to become unity as soon as the absorbed-photon energy reaches the dissociation limit. This behavior is clearly not observed, so that a notion of a purely repulsive upper state must be discounted. Indeed, the theoretical calculations indicate a bound upper state ${ }^{25}$ which suggests that the Huggins bands and the Hartley continuum are part of the same transition, the lower intensity of the Huggins bands being due to less favorable Franck-Condon factors. The general appearence of the Huggins bands, particularly the rise of intensity with increasing energy supports this interpretation ${ }^{25}$ and we shall adopt it for further discussion. The Huggins bands then represent the transition to vibrational levels within the stable region of the potential well, whereas the Hartley continuum arises from the more vertical transition to that portion of the potential surface which lies above the dissociation limit and where the $\mathrm{O}_{3}$ molecule is unstable. The Huggins bands have been identified mainly as sequences of the upper state bending and symmetric stretching modes ${ }^{26}$. The last rather diffuse band that can be discerned against the strongly increasing background of the continuum lies at $32100 \mathrm{~cm}^{-1}$, about $100 \mathrm{~cm}^{-1}$ below the here employed value of the dissociation limit. This observation does not preclude the existence of additional bands at higher energies submerged in the dissociation continuum.

Under these conditions, two factors may possibly cause a $\mathrm{O}\left({ }^{1} \mathrm{D}\right)$ quantum yield less than unity in this energy domain. The first is a shape of the potential energy surface such that it allows the dissociation into the $\mathrm{O}\left({ }^{1} \mathrm{D}\right)$ channel only along that reaction coordinate which is represented by one of

1 H. Levy, Adv. Photochem. 9, 369 [1974] ; S. C. Wofsy, J. C. McConnell, and M. B. McElroy, J. Geophys. Res. 77, 4477 [1972] ; P. Crutzen, Can. J. Chem. 52, 1569 [1974] and Tellus 26, 47 [1974] ; M. N. Nicolet, Can. J. Chem. 52, 1381 [1974] ; P. Warneck, Ber. Bunsenges. phys. Chem. 78, 192 [1974] and Tellus 26, 192 [1974].

2 H. I. Schiff, Ann. Géophys. 28, 67 [1972]. the two involved vibrational modes - say the stretching mode - whereas the contribution of the other vibrational mode comes into play only at higher energies. For this process to occur the coupling between the vibrational modes must be weak and the energy residing in the ineffective vibrational modes must be removed by either re-radiation or collisions. The observed $\mathbf{O}\left({ }^{1} \mathrm{D}\right)$ quantum yield would in this case reflect the partioning of energy among the two vibrational modes in the vicinity of the dissociation limit.

The second possibility is a perturbation of the upper state of the Huggins-Hartley system by other states, leading to predissociation into the $\mathrm{O}\left({ }^{3} \mathrm{P}\right)$ channel. As Simons et al. ${ }^{26}$ pointed out the asymmetric stretching mode would be affected most strongly by such a perturbation, explaining not only the lack of its observation, but also the occurrence of a continuous component of the spectrum below the $O\left({ }^{1} \mathrm{D}\right)$ dissociation limit. However, the observed bands in this spectral region are also rather diffuse indicating that even the symmetric stretching and bending modes are influenced by the perturbation. If it is assumed that this perturbation persists into the energy domain above the $O\left({ }^{1} \mathrm{D}\right)$ dissociation limit, a fraction of the excited ozone molecules would suffer predissociation into the $\mathrm{O}\left({ }^{3} \mathrm{P}\right)$ channel rather than undergo direct dissociation to yield $\mathrm{O}\left({ }^{1} \mathrm{D}\right)$. In this case the $\mathrm{O}\left({ }^{1} \mathrm{D}\right)$ quantum yield would indicate the relative efficiency of both processes.

The two processes just outlined as conceivably being responsible for an $\mathrm{O}\left({ }^{1} \mathrm{D}\right)$ quantum yield less than unity in the energy domain adjacent to the dissociation limit may be summarised briefly as: energy storage in an ineffective vibrational mode; and predissociation into the $\mathrm{O}\left({ }^{3} \mathrm{P}\right)$ channel. The present data cannot distinguish between these two processes.

The present work was performed as part of the program of the Sonderforschungsbereich 73 "Atmospheric Trace Components" receiving partial funding from the Deutsche Forschungsgemeinschaft. We are greatly indebted to E. Kudszus for assistence with the computer programmes.

3 K. H. Welge, Can. J. Chem. 52, a [1974].

4 Janaf, Thermochemical Tables, 2nd edition, D. R. Stull and H. Prophet, editors, Dow Chemical Cov., Midland, Michigan (USA) 1971.

5 I. T. N. Jones and R. P. Wayne, Proc. Roy. Soc. London A 319, 273 [1970].

6 H. Taube, Trans. Faraday Soc. 53, 656 [1957]. 
7 W. B. De More and O. F. Raper, J. Chem. Phys. 37, 2048 [1962].

8 W. B. De More and O. F. Raper, J. Chem. Phys. 44, 1780 [1966].

9 E. Castellano and H. J. Schumacher, Z. Phys. Chem. NF 65, 62 [1969].

10 R. Simonaitis, S. Braslavsky, J. Heicklen, and M. Nicolet, Chem. Phys. Lett. 19, 601 [1973].

11 S. Kuis, R. Simonaitis, and J. Heicklen, Dept. Chem., Pennsylvania State University, University Park, Pa., USA, private communication.

12 C. L. Lin and W. B. DeMore, J. Photochem. 2, 161 [1973].

13 Quoted by R. P. Wayne, Proc. Intern. Conf., Structure, Composition and Gen. Circulation of Upper and Lower Atmosphere and Possible Anthropogenic Perturbations, Melbourne Vol. 1, 363 [1974].

14 M. A. A. Clyne, B. A. Thrush, and R. P. Wayne, Trans. Faraday Soc. 60, 359 [1964]; P. N. Clough and B. A. Thrush, ibid. 63, 915 [1967].

15 P. M. Scott, K. F. Preston, R. J. Anderson, and L. M. Quick, Can. J. Chem. 49, 1808 [1971] ; and R. Simonaitis, R. I. Greenberg, and J. Heicklen, Int. J. Chem. Kinetics 4, 497 [1972].

16 R. F. Heidner, D. Husain, and J. R. Wiesenfeld, J. Chem. Soc. Faraday Trans. II 69, 927 [1973].

17 R. J. Cvetanovic, Can. J. Chem. 52, 1452 [1974].

18 R. D. Hudson, Can. J. Chem. 52, 1465 [1974] and references contained therein.
19 E. C. Y. Inn and Y. Tanaka, J. Opt. Soc. Amer. 43, 870 [1953].

20 M. Griggs, J. Chem. Phys. 49, 857 [1968].

21 G. Herzberg, Molecular Spectra and Molecular Structure III, Electronic Spectra and Electronic Structure of Polyatomic Molecules, D. van Nostrand Comp., Amsterdam 1966.

22 G. Herzberg, Molecular Spectra and Molecular Structure II, Infrared and Raman Spectra of Polyatomic Molecules, D. van Nostrand Comp., Amsterdam 1945, pp. 505 and 42 .

${ }^{23} \mathrm{Kuis}$ et al. considered the $A$-component of the angular momentum to be unavailable, but other possibilities exist also. They will not be considered here. - Since during the electronic transition the selection rules for the quantum numbers $J$ and $K$ guarantee the conservation of angular momentum, the concept advanced by Kuis et al. will be equivalent to the erection of a rotational barrier in the dissociating state with increasing rotational quantum number; see Ref. ${ }^{22}$.

24 R. S. Mulliken, Can. J. Chem. 36, 10 [1958].

25 P. J. Hay, T. H. Dunning, Jr., and W. Goddard III, Chem. Phys. Lett. 23, 457 [1973].

26 J. W. Simons, R. J. Paur, H. A. Webster III, and E. J. Bair, J. Chem. Phys. 59, 1203 [1973] and references cited therein. 